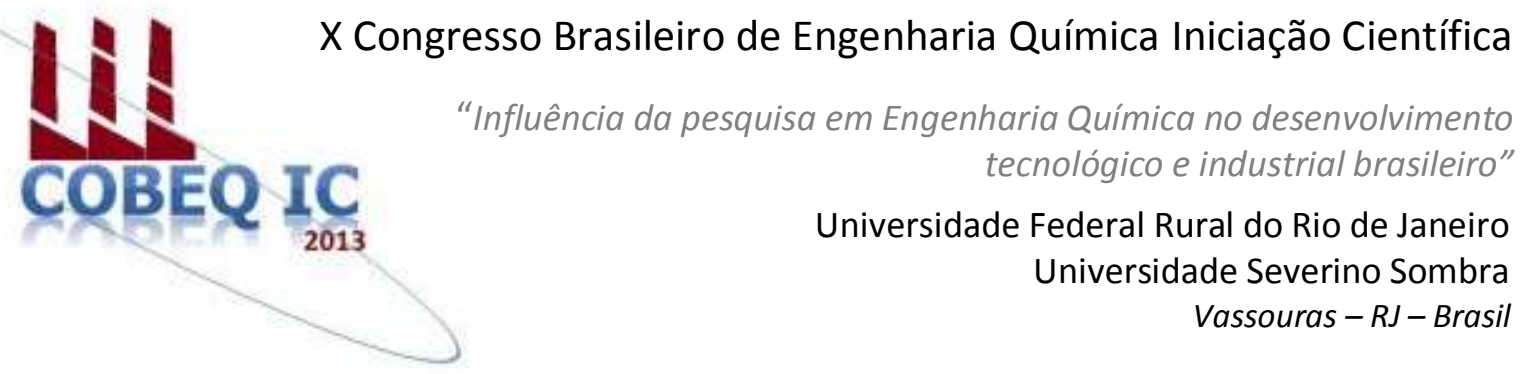

\title{
REAPROVEITAMENTO DO ÓLEO DE FRITURA EM PRODUTOS DE ALTO VALOR AGREGADO: ANÁLISE DE CUSTO.
}

\author{
SILVA $^{* 1}{ }^{1}$,J.M.; JESUS ${ }^{2}$, L. L.; NASCIMENTO,R.S.F. ${ }^{3}$; MENDES $^{4}$, M.F. \\ ${ }^{1}$ Aluno do DEQ/UFRRJ ${ }^{2}$ Aluna do Ensino Médio da Escola Presidente Dutra ${ }^{3}$ Aluno do Ensino \\ Médio da Escola Presidente Dutra ${ }^{4}$ Professor Adjunto IV - DEQ/UFRRJ \\ Departamento de Engenharia Química - Universidade Federal Rural do Rio de Janeiro \\ Endereço-UFRRJ, BR 465, km 07, Seropédica, CEP. 23.890-000, RJ, \\ email: marisamf@ufrrj.br
}

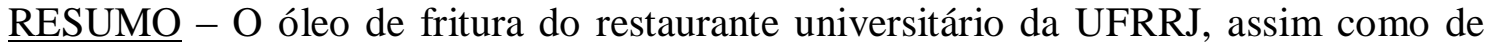
cantinas localizadas dentro do campus universitário, foi utilizado neste trabalho para produção de sabão através da reação de saponificação. O objetivo deste trabalho foi analisar o custo da produção de sabão e analisar a economia com a compra do mesmo pela UFRRJ, além de visar uma alternativa viável e sustentável para a reutilização do óleo do restaurante universitário. De acordo com os resultados, verificou-se que a produção de sabão em escala piloto confere a universidade um gasto de $\mathrm{R} \$ 29,42 /$ ano e um lucro de $\mathrm{R} \$ 7,19 / \mathrm{ano}$.
\end{abstract}

Palavras chave: sustentabilidade, sabão, óleo residual

\section{INTRODUÇÃO}

A produção de óleo residual é crescente no mundo todo e o seu descarte inapropriado, como em esgotos, mares e lagos, é considerado crime ambiental. No Brasil, não há leis que indiquem o descarte correto do óleo e a falta de informação por parte da população faz com que o mesmo seja descartado nos esgotos, ocasionando entupimento e quando descartados em mares e lagos ocasiona o mortandade de espécies aquáticas. Segundo Felizardo et al. (2006), o óleo dificulta a operação das plantas de tratamento de água, visto que é um contaminante para o tratamento secundário e terciário.

Devido a isso, atualmente, vários destinos tem sido estudados para esse óleo residual, como a produção de biodiesel, a produção de energia através da queima do mesmo e a produção de sabões e sabonetes.

Desta forma, a reutlização do óleo residual para produção de sabão é uma alternativa viável, economicamente e ambientalmente vantajosa.

O sabão é produzido através da reação de saponificação dos triglicerídeos presentes no óleo, com hidróxido de sódio, sob aquecimento. Esta reação é mostrada na Figura 1.

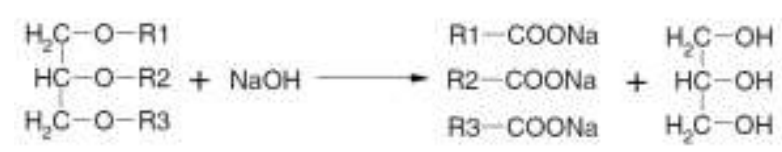

Figura 1 - Reação de Saponificação. 


\section{MATERIAIS E MÉTODOS}

\section{Materiais}

O óleo utilizado na produção de sabão foi doado pelo restaurante universitário da UFRRJ e por cantinas localizadas dentro do campus universitário e não sofreu qualquer pré-tratamento.

O hidróxido de sódio P.A. e o hidróxido de potássio P.A. foram obtidos pela Vetec Química Fina Ltda. (Rio de Janeiro, Brasil).

\section{Metodologia Experimental}

\section{Determinação do índice de saponificação}

Foram preparadas soluções de hidróxido de potássio e ácido clorídrico $0,5 \mathrm{~mol} / \mathrm{L}$. Pesou-se cerca de $15 \mathrm{~g}$ de óleo em um erlenmeyer e adicionou-se $40 \mathrm{~mL}$ de hidróxido de potássio. Em um outro erlenmeyer foram adicionados apenas $40 \mathrm{~mL}$ de solução de hidróxido de potássio. Ambas as amostras foram colocadas em refluxo, como mostra a Figura 2, por cerca de 40 minutos e sob aquecimento a $100{ }^{\circ} \mathrm{C}$.

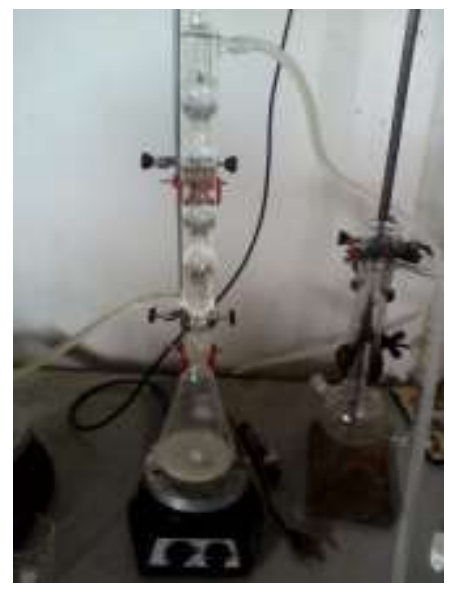

Figura 2: Representação da amostra de óleo em refluxo

Após o término do refluxo, as amostras foram tituladas com solução de ácido clorídrico 0,5 mol/L, como mostrado na Figura 3.

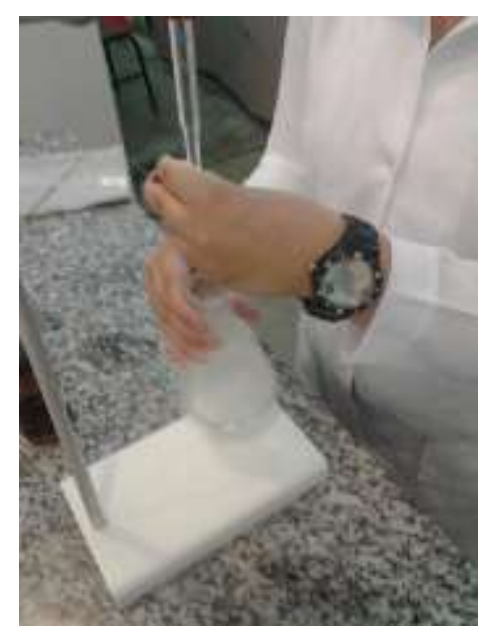

Figura 3: Representação da titulação da amostra.

\section{Produção de sabão}

Após determinado o índice de saponificação, foram pesados cerca de $18 \mathrm{~g}$ de hidróxido de sódio e dissolvidos em água destilada. Utilizando o densímetro foi determinada a densidade do óleo. Mediu-se $250 \mathrm{~mL}$ do óleo e o mesmo foi submetido ao aquecimento a $100^{\circ} \mathrm{C}$. O hidróxido de sódio foi adicionado aos poucos, até que se chegasse a uma mistura mais viscosa, como mostrado pela Figura 4.

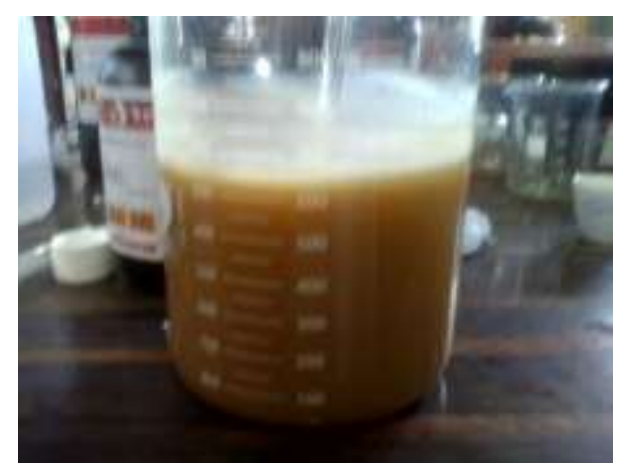

Figura 4: Representação da conclusão da adição do $\mathrm{NaOH}$ ao óleo.

Adicionou-se corantes e essências e transportou-se a amostra para as formas como mostrado na Figura 5. 


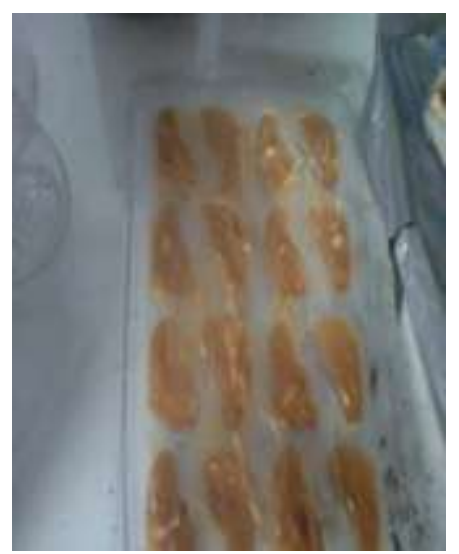

Figura 4: Representação da etapa final de adição do sabão às formas.

\section{RESULTADOS E DISCUSSÕES}

O índice de saponificação da amostra representa a quantidade de hidróxido de potássio em miligramas necessários para conversão de $1 \mathrm{~g}$ de óleo em sabão e foi calculado através da equação 1 .

$\mathrm{IS}=\frac{(\mathrm{Vb}-\mathrm{Va}) \times \mathrm{N} \times \mathrm{fc} \times 56,1}{\mathrm{~m}}$

onde $\mathrm{Fc}$ é o fator de correção do $\mathrm{HCl}$, IS é o índice de saponificação da amostra de óleo (mg de $\mathrm{KOH} / \mathrm{g}$ de óleo), m é a massa de óleo pesada (g), $\mathrm{N}$ é a normalidade do $\mathrm{HCl}$, Va é o volume $(\mathrm{mL})$ de $\mathrm{HCl}$ para a titulação da amostra de óleo e $\mathrm{Vb}$ é o volume $(\mathrm{mL})$ de $\mathrm{HCl}$ para a titulação da amostra de $\mathrm{NaOH}$.

Desta forma os resultados obtidos das amostras representados na Tabela 1 .

Tabela 1: Índice de saponificação em mg de $\mathrm{KOH}$ por g de óleo

\begin{tabular}{c|c|c|c|c}
\hline Amostra & $\begin{array}{c}\text { Massa } \\
\text { de óleo }(\mathrm{g})\end{array}$ & $\begin{array}{c}\text { Densidade } \\
\left(\mathrm{g} / \mathrm{cm}^{3}\right)\end{array}$ & $\begin{array}{c}\text { Temperatura } \\
\left({ }^{\circ} \mathrm{C}\right)\end{array}$ & $\begin{array}{c}\text { Índice de saponificação } \\
(\mathrm{mg} \text { KOH/g de óleo })\end{array}$ \\
\hline 1 & $15,1065(0,0490)$ & 0,96144 & 24,2 & $63,89( \pm 0,4773)$ \\
\hline 2 & $15,4437( \pm 0,0422)$ & 0,90533 & 27,3 & $63,1( \pm 0,2894)$ \\
\hline 3 & $15,4095( \pm 0,1862)$ & 0,92126 & 28,9 & $64,03( \pm 0,1676)$ \\
\hline 4 & $15,1521( \pm 0,0834)$ & 0,92195 & 27,4 & $71,14( \pm 0,4388)$ \\
\hline 5 & $15,3396( \pm 0,1965)$ & 0,8951 & 37,5 & $60,58( \pm 0,6820)$ \\
\hline
\end{tabular}

Utilizando os valores dos índices de saponificação e iniciando, assim, a produção do sabão, pode-se realizar uma análise econômica baseando-se na produção do sabão produzido com $200 \mathrm{~mL}$ de óleo e $18 \mathrm{~g}$ de $\mathrm{NaOH}$ conforme mostra a Figura 6.

Os cálculos econômicos preliminares foram realizados considerando-se:

a) 22 dias úteis ao mês, b) uma geração de óleo residual pelo restaurante universitário de 230 L/óleo por semana e

c) o preço médio de sabão neutros nos mercados da região de Seropédica, ao redor de $\mathrm{R} \$ 0,85$. 


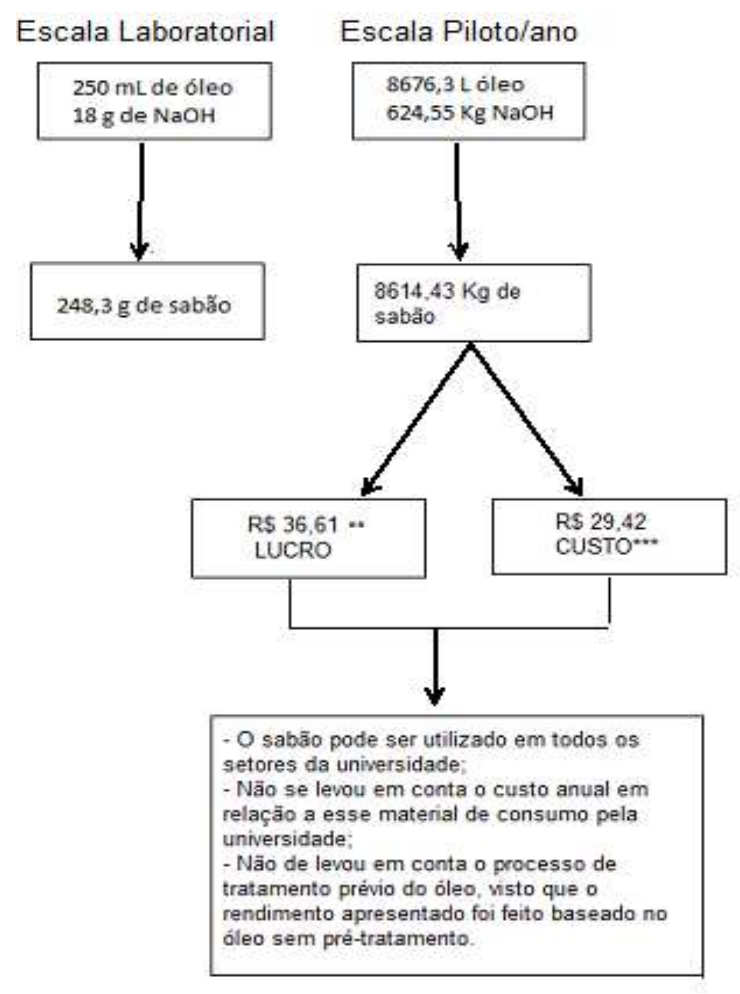

Figura 6: Fluxograma da análise econômica da produção de sabão.

\section{CONCLUSÃO}

De acordo com os resultados, conclui-se que a produção de sabão é uma fonte alternativa, economicamente viável para a recuperação do óleo residual, já que foi obtido um lucro de $\mathrm{R} \$ 36,61$, ultrapassando o custo total de $\mathrm{R} \$ 29,42$.

Assim, além de ser uma fonte alternativa de renda, também é ambientalmente vantajosa.

\section{REFERÊNCIAS BIBLIOGRÁFICAS}

FELIZARDO, P.; CORREIA, M. J. N.; RAPOSO, I.; MENDES, J. F.; BERKEMEIR, R.; BORDADO, J. M. Production of biodiesel from waste frying oils. Waste Management, v. 26, p. 487-494, 2006.

MOURA, B. S., Transesterificação Alcalina de Óleos Vegetais para Produção de Biodiesel: Avaliação Técnica e Econômica, Dissertação, Instituto de Tecnologia, Curso de Pós-graduação em Engenharia Química, UFRuralRJ, 2010.
PHAN, A. N.; PHAN, T. M. Biodiesel production from waste cooking oils. Fuel, v. 87, p. 3490-3496, 2008.

\section{AGRADECIMENTOS}

À FAPERJ, pela bolsa concedida;

Ao $\mathrm{CNPq}$, pela ajuda financeira pelo projeto Forma Engenheiros/Vale/2012, "Recuperação de recursos energéticos para a produção de biocombustíveis";

À FAPERJ, pelo projeto $n^{\circ}$ E26/111.135/2010, "Do óleo ao sabão e biodiesel - recuperação de resíduos em produtos de alto valor agregado". 